\title{
The influence of molecular weight on the properties of polyacetal/hydroxyapatite nanocomposites. Part 1. Microstructural analysis and phase transition studies
}

\author{
Kinga Pielichowska
}

Received: 10 April 2011 / Accepted: 10 October 2011 / Published online: 22 February 2012

(C) The Author(s) 2012. This article is published with open access at Springerlink.com

\begin{abstract}
In this work the influence of molecular weight of three polyoxymethylene (POM) copolymers on the properties of (POM)/hydroxyapatite (HAp) nanocomposites for long-term bone implants have been investigated by various physicochemical methods. Electron microscopy observations confirmed uniform dispersion of HAp in the polymer matrix, whereby DSC results show that HAp influences the degree of crystallinity of POM matrix. Temperature modulated differential scanning calorimetry (TMDSC) was applied to study the melting and recrystallization processes of POM matrix - it was found that with decreasing of POM molecular weight the amout of reversible melting increases. WAXD results show no shift in $2 \theta$ for pure POM copolymers and all POM/hydroxyapatite nanocomposites, indicating that the addition of HAp does not change the hexagonal system of POM. For all three copolymers, Young's modulus increases with increasing hydroxyapatite concentration, whereby elongation at break decreases. On the contrast, HAp concentration does not have a significant influence on the tensile strength.
\end{abstract}

Keywords Biomaterials · Nanocomposites · Thermal properties $\cdot$ Mechanical properties

\section{Introduction}

Polyacetal polymers have excellent properties such as good wear friction, mechanical stability, chemical resistance and

K. Pielichowska $(\triangle)$

Faculty of Materials Science and Ceramics, Department of Biomaterials, AGH University of Science and Technology,

Al. Mickiewicza 30,

30-059 Kraków, Poland

e-mail: kingapie@agh.edu.pl the creep durability. The polyacetal copolymers are obtained by cationic copolymerization of trioxane with comonomer such as cyclic ethers and cyclic formals, and then are subjected to thermal treatment after copolymerization to remove the unstable ends of the polymers $[1,2]$. The advantage in the production of polyacetal copolymer is the possibility to introduce the stable end into the polymer backbone. The polyacetal copolymers show high heat stability and a longterm mechanical and physical properties, although they have lower crystallinity and lower short-term mechanical strength in comparison with polyacetal homopolymers [3, 4]. For these beneficial properties, they have been applied to replace metals and ceramics in microelectronic packaging, aerospace, automotive, and biomedical applications $[1,5,6]$.

Polyacetal has been used in different joints, but also as heart valve replacements. While it is a well-known engineering polymer and has been applied previously in orthopaedic implants (in e.g. hip and knee prostheses), there is little data on the effect of long-term exposure to the physiological environment on its mechanical properties [7,8]. The use of polyoxymethylene (Delrin ${ }^{\circledR}$ ) in total hip protheses was first suggested in the mid-1960s, and since 1970, Delrin acetal polymer has been used in the Christiansen total hip prosthesis and endoprosthesis [9].

One of the most important groups of polymer-ceramics composites are polymer/hydroxyapatite materials. Hydroxyapatite $\left[\mathrm{Ca}_{10}\left(\mathrm{PO}_{4}\right)_{6}(\mathrm{OH})_{2}\right](\mathrm{HAp})$ is a well known bioceramics which is chemically similar to human inorganic hard tissue [10].

It is well-known that two critical factors in producing (nano)composites with bone-like properties are (i) a good interfacial adhesion between organic polymers and inorganic HAp, and (ii) the uniform dispersion of HAp at nano-level in the polymer matrix $[11,12]$. Lack of adhesion between HAp particles and polymer matrix usually results in early 
failure at the interface of both phases. On the other hand, if HAp is not uniformly dispersed in polymer matrix through proper processing methods it may agglomerate and the resulting composite material is characterised by poor mechanical properties. In the last decade considerable effort was made to produce and characterise polymer/nano-HAp systems that resembles bone structure to the higher extent that classical microcomposites do.

In this paper the influence of average molecular weight of polyacetal copolymer on crystallinity, microstructure, and interactions between components, as well as on the mechanical properties of POM/Hap nanocomposites for long-term bone implants, is presented.

\section{Experimental}

Materials and processing

Three commercial grades of POM copolymers T200, T300 and T411 (Tarnoform ${ }^{\circledR}$ ) (denoted as T2, T3 and T4, respectively), with melt flow rate (MFR 190/2.16, ISO 1133) of 2.5, 9.0 and $13 \mathrm{~g} / 10 \mathrm{~min}$, respectively, were supplied by Z. A. Tarnów-Mościce. Average molecular are presented in Table 1.

Hydroxyapatite $\mathrm{Ca}_{10}\left(\mathrm{PO}_{4}\right)_{6} \mathrm{OH}_{2}$ nanopowder with a nanoparticle size below $100 \mathrm{~nm}$ (99\% of particles) was product of nGimat Co. (Atlanta, USA).

$\mathrm{POM}$ and POM/HAp nanocomposites were prepared by melt processing method. Firstly, POM was air-dried, and then the POM and HAp were mechanically mixed, and finally extruded in a double screw extruder (ThermoHaake PolyLab PTW 16/25) at a rotary speed of $50 \mathrm{rpm}$. The temperature profiles of the barrel were: for T200 185-190$190-190{ }^{\circ} \mathrm{C}$, for T300 $185-190-190-185{ }^{\circ} \mathrm{C}$ and for T411 190-190-190-185 ${ }^{\circ} \mathrm{C}$. Compositions were then shaped by using DSM laboratory injection moulding machine. Composition of POM/HAp nanocomposites was presented in Table 2

\section{Techniques}

Molecular weight was determined by GPC according to ASTM D5296-05 standard. The measurements were

Table 1 The average molecular weight for POM copolymers

\begin{tabular}{lrrr}
\hline Sample & \multicolumn{1}{l}{ Mn } & Mw & Mw/Mn \\
\hline T2 & 9368 & 100768 & 10,76 \\
T3 & 8614 & 74727 & 8,67 \\
T4 & 10203 & 68377 & 6,70 \\
\hline
\end{tabular}

Table 2 Samples description

\begin{tabular}{ll}
\hline Composition & Ratio $[\mathrm{w} / \mathrm{w}]$ \\
\hline T2/HAp & $99.5 / 0.5$ \\
& $99.0 / 1.0$ \\
& $97.5 / 2.5$ \\
& $95.0 / 5.0$ \\
& $90.0 / 10.0$ \\
T3/HAp & $99.5 / 0.5$ \\
& $99.0 / 1.0$ \\
& $97.5 / 2.5$ \\
& $95.0 / 5.0$ \\
& $90.0 / 10.0$ \\
T4/HAp & $99.5 / 0.5$ \\
& $99.0 / 1.0$ \\
& $97.5 / 2.5$ \\
& $95.0 / 5.0$ \\
& $90.0 / 10.0$ \\
\hline
\end{tabular}

performed at $40^{\circ} \mathrm{C}$ on a VE2001 Viscotek GPC System with a RI-VE 3580 (Viscotek) detector, using a PL HFIP gel and HFIP 603 E910606 column.

For the DSC measurements Mettler-Toledo DSC 822e, operating in dynamic mode, was employed. The conditions were: samples of $c a .5 \mathrm{mg}$, the heating/cooling rate of $10 \mathrm{~K} /$ min, atmosphere: argon, intracooler was used for cooling. MT-DSC (Mettler-Toledo 822e) measurement condidtions were: amplitude $0.5 \mathrm{~K}$, period $45 \mathrm{~s}$ and underlying heating rate $1 \mathrm{~K} / \mathrm{min}$. Transmission electron microscope LEO $912 \mathrm{AB}$ was applied and samples were cut by using of ultramicrotome MTX (RMC). Scanning electron microscope (SEM) Nova Nano SEM 200, equipped with an energy dispersive X-ray analyser (Link ISIS-EDX) was used to investigate the surface morphology of carbon-coated samples at the energy of the electron beam of $5 \mathrm{kV}$. For optical microscopy observations an optical/fluorescence microscopy (Zeiss Axiovert 40 CFL, Carl Zeiss, Germany) was employed. WAXD measurements were performed using Philips X'Pert Pro MD diffractometer. Radiation used was $\mathrm{CuK}_{\alpha 1}$ line monochomatized by $\mathrm{Ge}(111)$ monochromator. Standard Bragg-Brentano geometry with $\Theta-2 \Theta$ setup was applied $\left(0.008^{\circ}\right.$ step size and $15-60^{\circ} 2 \mathrm{H} \Theta$ range $)$. All measurements were performed at room temperature. IR spectra of the samples were recorded at elevated temperatures using a HATR PIKE attachment with ZnSe crystal on a Bio-Rad FTS 165 Fourier transform infrared (FTIR) spectrometer at a resolution of $2 \mathrm{~cm}^{-1}$. Mechanical tests were carried out using a Zwick machine in the tensile mode at upper crosshead speed of $50 \mathrm{~mm} / \mathrm{min}$ at ambient temperature according to ISO 527. Tensile specimens according to ISO 3167 with thickness $1.53 \pm 0.02 \mathrm{~mm}$ and width $4.91 \pm$ $0.01 \mathrm{~mm}$ were applied. The yield strength was determined from the upper yield point and the fracture strain was the 
elongation at break from the tensile curve. The reported mechanical properties were calculated by averaging measurements of three specimens.

\section{Results and Discussions}

From Figs. 1, 2, 3 and 4 it can be observed that the dispersion of HAp in the polymer matrix was uniform-HAp is present in the polymer matrix in form of single nanoparticles or two- or three particles group even for the sample with $5 \%$ HAp.

Fracture surface of POM and POM/HAp nanocomposites can be observed in Figs. 2, 3, and 4.

It is believed that voids appear to be concentrated within this spherulitic structure, leading to the hypothesis that the crack path is inside the spherulites, and that cavitation occurs in the amorphous regions of the spherulite. As in
Fig. 1 TEM microphotographs of T2/0.5\% HAp (a), T2/5.0\% HAp (b), T3/0.5\% HAp (c), T3/ $5.0 \%$ HAp (d), T4/0.5\% HAp (e) and T4/5.0\% HAp (f)

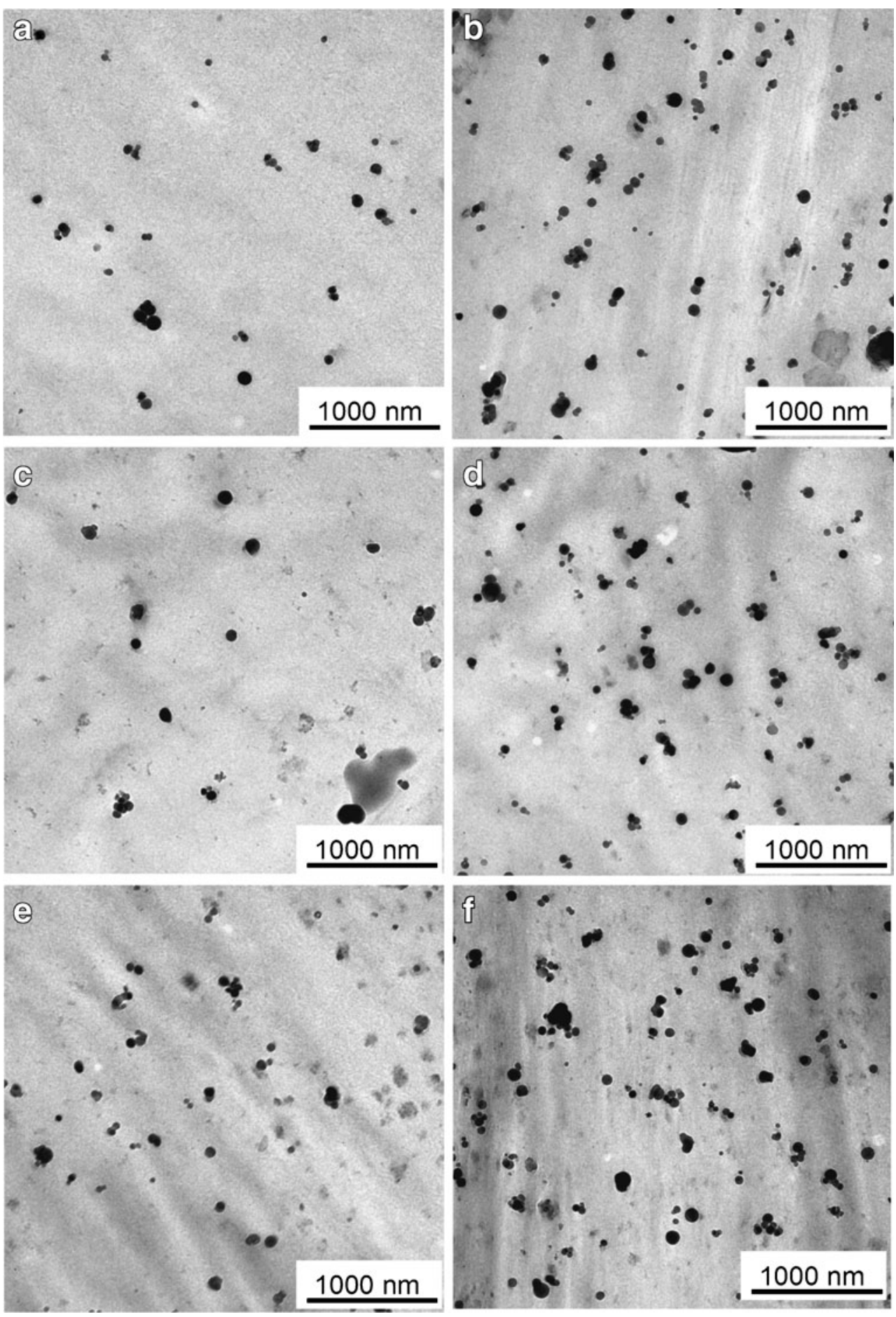


Fig. 2 SEM microphotographs of fractured surfaces of T2 (a, b), T2/0,5\% HAp (c, d) and T2/ $5 \% \operatorname{HAp}(\mathbf{e}, \mathbf{f})$
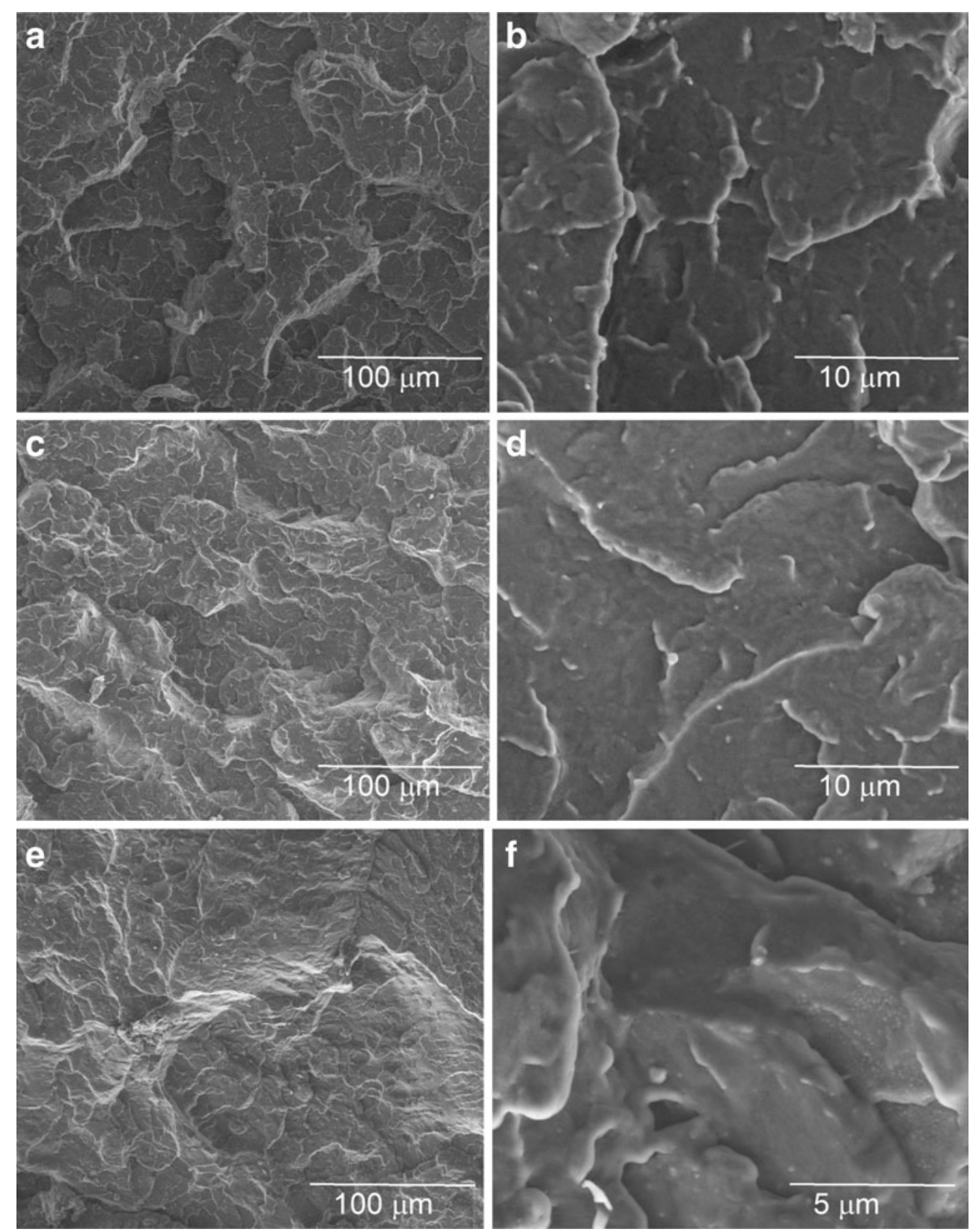

rubber toughened polymers, yielding at room temperature in bulk POM is accompanied by extensive cavitation and stress whitening. Such cavitation processes enable attainment of high elongations at break without necking in tensile tests. Voiding in POM involves entanglement loss due to chain cutting. This may lead to a decrease in the density of tie molecules that interconnect the crystalline regions and, consequently, to a decrease of the load carrying capacity of the material [13]. The most smooth surface with the smallest voids of fractured sample was revealed for T4 copolymer and its nanocomposites. It can be associated with the higher degree of crystallinity for T4 and T4/HAp nanocomposites. Moreover, at higher magnifications numerous small POM crystallites are visible. The larger voids were found for $\mathrm{T} 2$ and then for T2/HAp nanocomposites due to the lowest degree of crystallinity of pure POM. For pure POM lack of nucleating agents in the sample leads to homogeneous nucleation with formation of smaller amounts of primary nuclei and formation of larger and more perfect spherulitic structures. In spite of higher degree of crystallinity for T2/ $0.5 \%$ HAp sample, the larger amounts of voids was observed in this nanocomposite than for pure POM. In POM/ HAp nanocomposites with low HAp concentraction, HAp can act as nucleating agent for POM and during POM crystallization it can be observed both homogeneous and heterogeneous nucleation as well as more rapid POM 
Fig. 3 SEM microphotographs of fractured surfaces of T3 (a, b), T3/0,5\% HAp (c, d) and T3/ $5 \% \operatorname{HAp}(\mathbf{e}, \mathbf{f})$
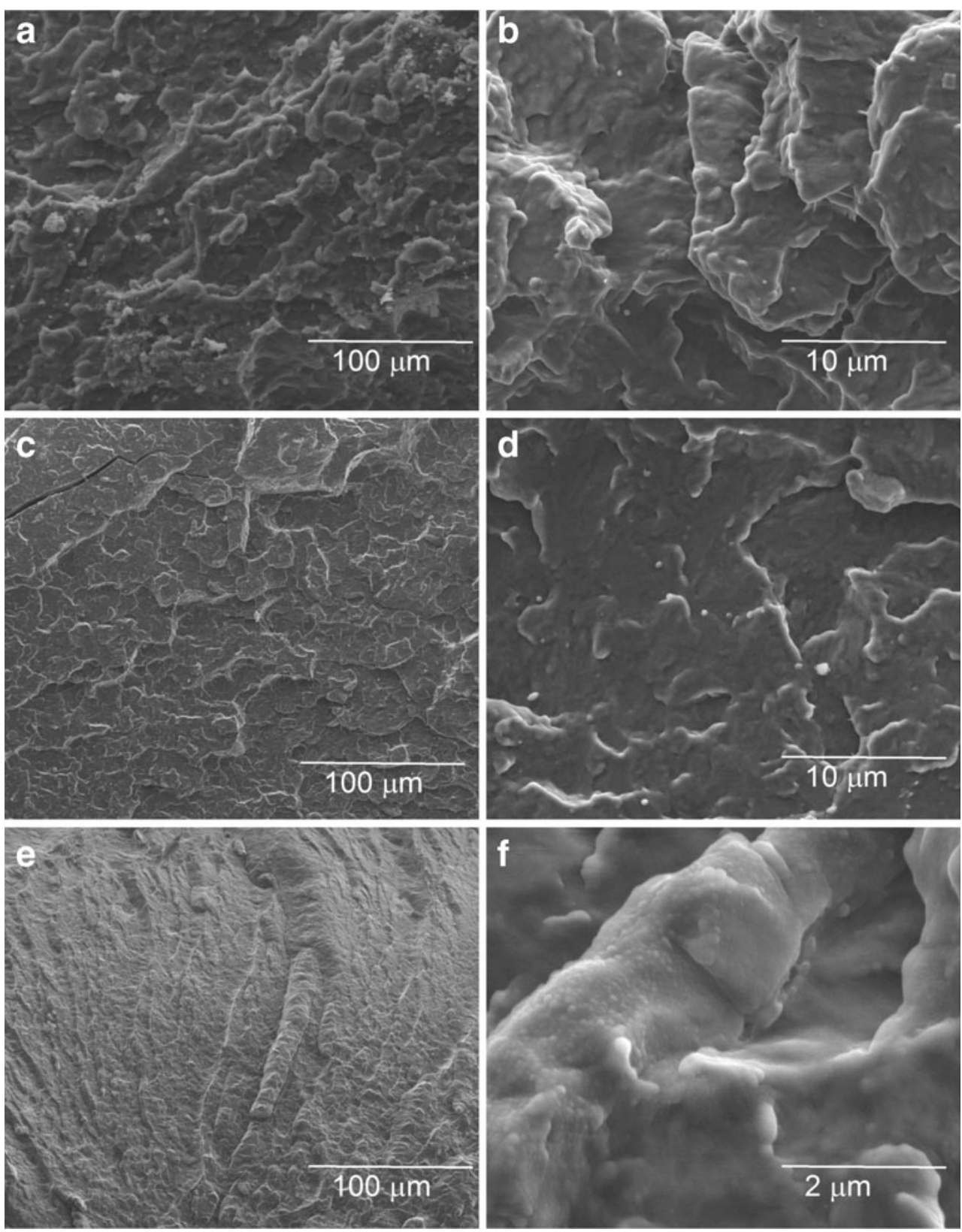

crystallization - it leads to formation of larger amounts of spherulites which are, however, less perfect-Fig. 5. During fracture of such a structure larger amounts of voids are produced.

Results of DSC investigations of all POM copolymers and POM/HAp nanocomposites are presented in Table 3 and Fig. 6.

DSC results from the first heating run are strongly influenced by processing conditions (rapid cooling during injection moulding) that affect the structure and thermal properties of POM and its nanocomposites with HAp. During melting in DSC measurement conditions two or three overlapping endothermic processes (in some cases with clearly visible two or three maxima) have been observed for all investigated samples. Similar effect in POM homopolymer was observed by Bershtein et al. [14] at lower heating rates. They observed double melting peak under different heating rates, and the height and temperature of the new, second peak increased with decreasing a heating rate. This effect was attributed to reorganization or/and recrystallization processes occurring in POM crystallites, which under certain conditions are metastable [15].

From our DSC results it can be observed that melting and crystallizations temperature and heat of melting and crystallization depends on both copolymer molecular weight and HAp content. With an increase of POM copolymer molecular weight melting temperature as well as crystallization 
Fig. 4 SEM microphotographs of fractured surfaces of T4 (a, b), T4/0,5\% HAp (c, d) and T4/ $5 \% \operatorname{HAp}(\mathbf{e}, \mathbf{f})$
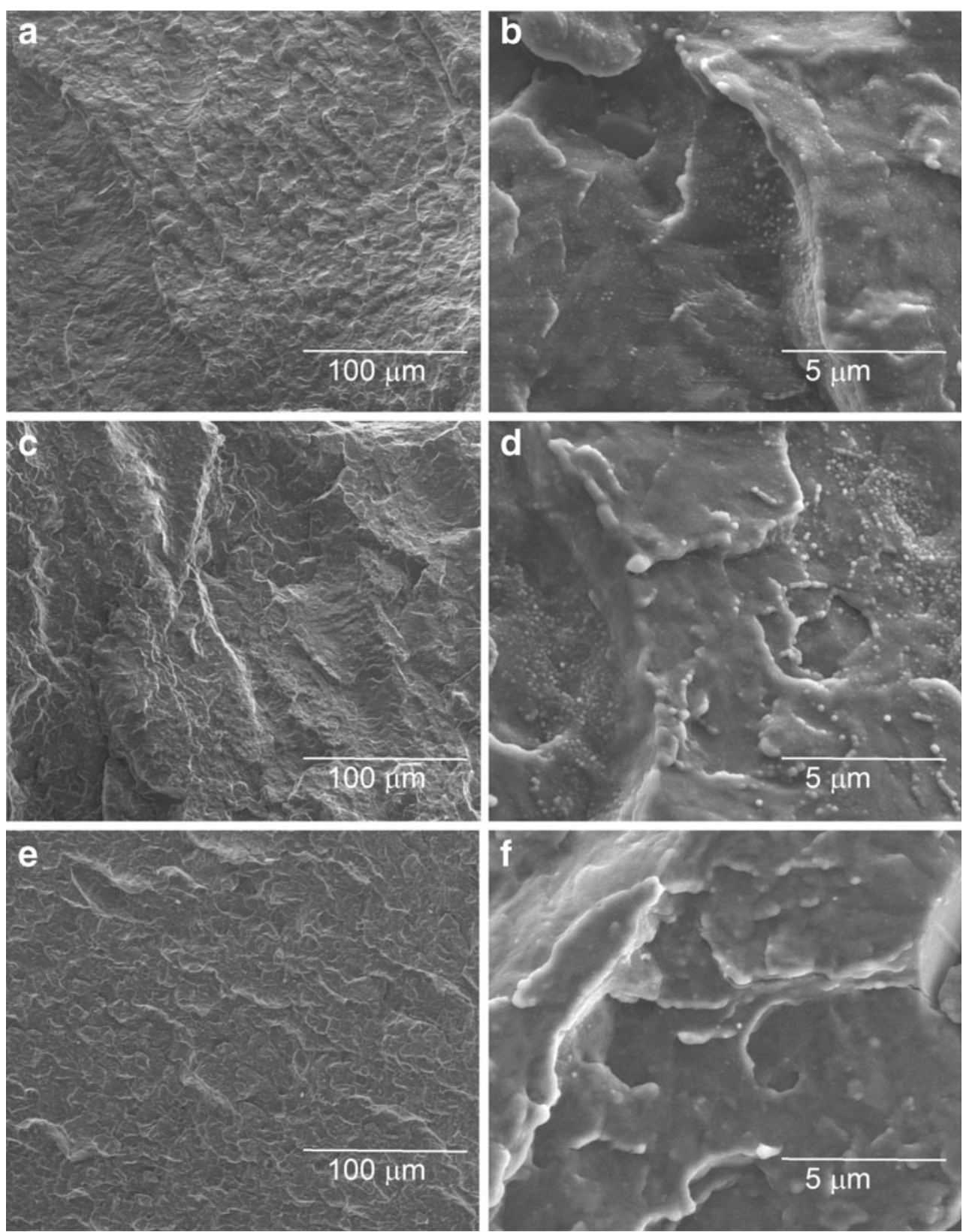

temperature increase - as a consequence T2 copolymer melts in the widest temperature range (about $25^{\circ}$ ) and crystallizes at the highest supercooling while the T4 copolymer melts in the narrowest temperature range (about $19^{\circ}$ ) and crystallizes at the lowest supercooling.

Next, the degree of crystallinity $\left(\mathrm{X}_{\mathrm{c}}\right)$ was calculated using the formula:

$X_{c}=\frac{\Delta H-\Delta H_{a}}{\Delta H_{m}^{0}}=\frac{\Delta H_{m}}{\Delta H_{m}^{o}}$

where: $\Delta H_{m}^{o}$ - heat of melting of $100 \%$ crystalline polymer (326,3 J/g for POM) [16], $\Delta \mathrm{H}_{\mathrm{m}}$ - heat of melting of polymer under investigation. determined by DSC. $X_{c}$ values of investigated samples after first and second heating run are presented in Table 4.

For the first heating run it can be observed that for T2 copolymer the degree of crystallinity increases, and for T3 and T4 copolymers slightly decreases with an increase of HAp content. Moreover, it can be seen that the degree of crystallinity of pure POM copolymers is the lowest for T2 and the highest for T4 - the degree of crystallinity increases with a decrease of molecular weight. In the second heating run similar tendency can be observed. These results suggest that HAp nanoparticles in T2 and T3 copolymers act as effective nucleating sites, whereby for $\mathrm{T} 4$ the nanofiller behaves as an 
Fig. 5 OM microphotographs of T2 (a), T2/5.0\% HAp (b), T3 (c), T3/5.0\% HAp (d), T4 (e) and $\mathrm{T} 4 / 5.0 \%$ HAp (f)
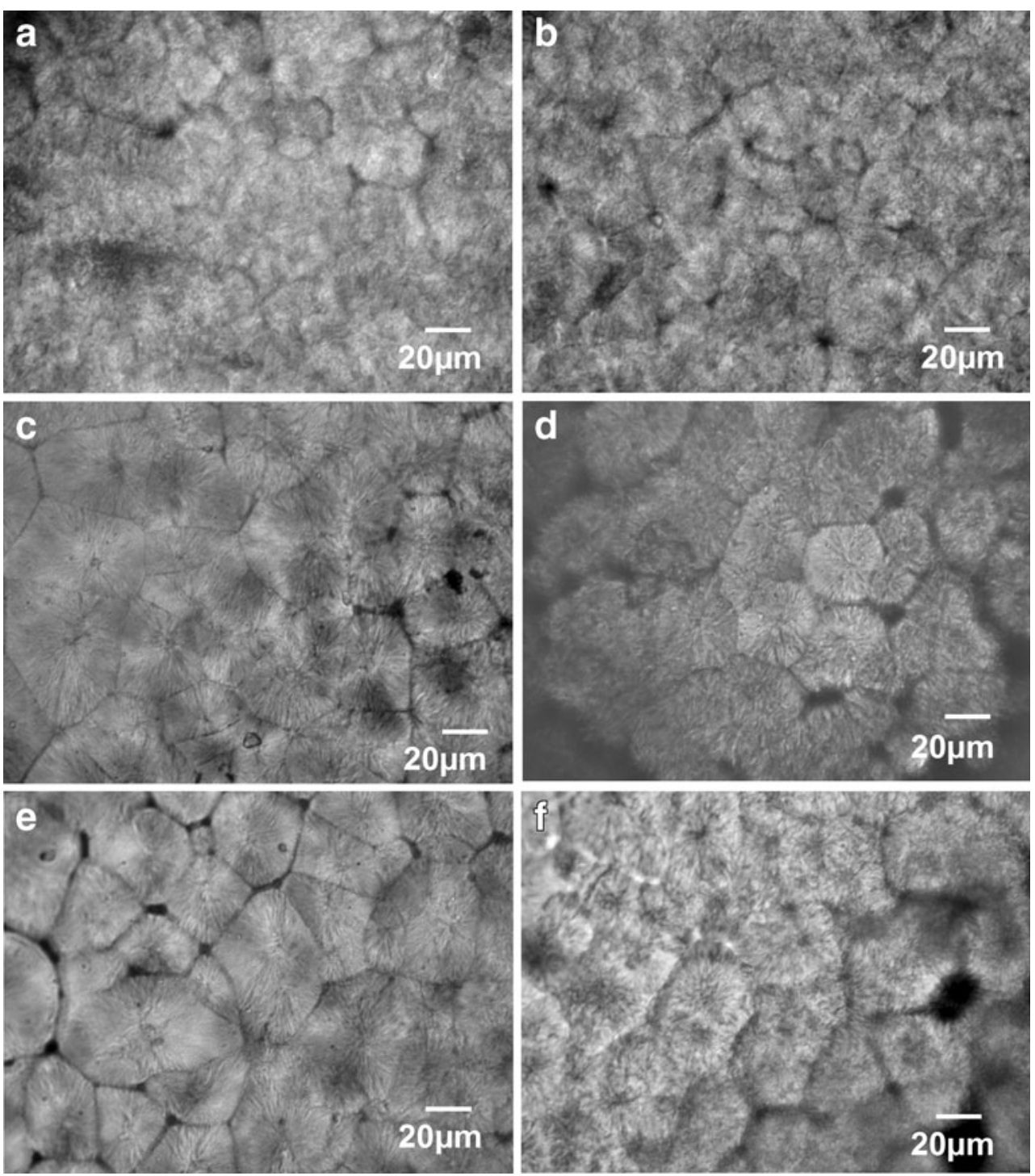

impurity and hinders POM crystallization. It should also be noted that higher degree of crystallinity was observed for the second heating run (at least 5\%)-it confirms previous observation that in injection moulding conditions larger fraction of metastable crystallites as well as large amount of amorphous phase are formed.

A DSC heating scan on a typical semi-crystalline polymer contains many non-equilibrium effects, including a large amount of reversible melting due to metastability of crystal morphologies [17]. To get more insight into the nature of melting and crystallization process of $\mathrm{POM}$ and $\mathrm{POM} / \mathrm{HAp}$ nanocomposites TMDSC experiments were performed. The modulated temperature and resultant modulated heat flow can be deconvoluted using a Fourier transform to give reversing and non-reversing components [18]. The reversible and non-reversible signals reveal the thermodynamic and kinetic characteristics of the phase transitions.
Sauer et al. [19] described methods for interpreting the TMDSC results for the polymer melting processes. The nonreversing endothermic signal is typically due to complete melting of separate lamellae or stacks of lamellae. The reversing endothermic signal is due to partial melting of lamellae. They are then able to rapidly recrystallize due to templating of the just melted chains as they recrystallize on existing crystals. Crystallization exotherms only contribute to the nonreversing signal, making this a very powerful technique for separation of exotherms from glass transitions, reversible melting, or other heat capacity related events [20].

Results of the TMDSC measurements for melting and crystallization processes of $\mathrm{T} 2$ and $\mathrm{T} 2 / 2.5 \% \mathrm{HAp}$ nanocomposites (for T3, T4 and their nanocomposite run of TMDSC curves are quite similar) are shown in Fig. 7 and Table 5.

From Fig. 6 it can be observed that the shape of TMDSC curves during melting and crystallization of POM and POM/ HAp nanocomposites for all POM copolymers is similar. In 
Table 3 Temperature and heat of melting and crystallization of POM and POM/HAp nanocomposites measured during first heating and cooling

\begin{tabular}{|c|c|c|c|c|c|c|c|c|}
\hline \multirow[t]{2}{*}{ Sample } & $\mathrm{T}_{\text {onset }}\left[{ }^{\circ} \mathrm{C}\right]$ & $\mathrm{T}_{\max }\left[{ }^{\circ} \mathrm{C}\right]$ & $\mathrm{T}_{\text {end }}\left[{ }^{\circ} \mathrm{C}\right]$ & $\begin{array}{l}\text { Heat of phase } \\
\text { transition }[\mathrm{J} / \mathrm{g}]\end{array}$ & $\mathrm{T}_{\text {onset }}\left[{ }^{\circ} \mathrm{C}\right]$ & $\mathrm{T}_{\max }\left[{ }^{\circ} \mathrm{C}\right]$ & $\mathrm{T}_{\text {end }}\left[{ }^{\circ} \mathrm{C}\right]$ & $\begin{array}{l}\text { Heat of phase } \\
\text { transition }[\mathrm{J} / \mathrm{g}]\end{array}$ \\
\hline & Melting & & & & Crystallizat & & & \\
\hline
\end{tabular}

$\mathrm{T} 2$

\begin{tabular}{|c|c|c|c|c|c|c|c|c|}
\hline $\mathrm{T} 2$ & 151.0 & 170.5 & 175.1 & 144.7 & 148.3 & 144.8 & 134.1 & 151.0 \\
\hline $\mathrm{T} 2 / 0.5 \%$ HAp & 158.6 & 169.8 & 177.0 & 148.4 & 148.4 & 142.9 & 133.2 & 154.2 \\
\hline T2/1.0\% HAp & 159.3 & 166.8 & 185.1 & 149.7 & 148.4 & 142.5 & 132.5 & 157.5 \\
\hline $\mathrm{T} 2 / 2.5 \%$ HAp & 156.5 & 170.1 & 175.0 & 152.4 & 148.7 & 143.9 & 133.6 & 157.3 \\
\hline T2/5.0\% HAp & 119.7 & 169.5 & 175.2 & 147.6 & 148.6 & 143.0 & 133.4 & 154.7 \\
\hline T2/10.0\% HAp & 157.2 & 170.8 & 175.3 & 146.4 & 148.5 & 143.0 & 132.3 & 158.1 \\
\hline \multicolumn{9}{|l|}{$\mathrm{T} 3$} \\
\hline $\mathrm{T} 3$ & 151.5 & 170.4 & 176.4 & 157.1 & 149.3 & 146.6 & 137.2 & 164.4 \\
\hline T3/0.5\% HAp & 157.5 & 170.0 & 174.9 & 155.0 & 149.5 & 147.0 & 137.6 & 165.0 \\
\hline T3/1.0\% HAp & 159.9 & 171.0 & 175.7 & 158.6 & 149.2 & 145.9 & 136.1 & 165.6 \\
\hline T3/2.5\% HAp & 80.9 & 166.8 & 191.5 & 156.9 & 149.4 & 146.6 & 136.3 & 164.5 \\
\hline T3/5.0\% HAp & 157.8 & 170.6 & 175.8 & 154.0 & 149.5 & 146.6 & 136.2 & 163.7 \\
\hline T3/10.0\% HAp & 161.3 & 169.5 & 174.8 & 146.7 & 149.6 & 147.4 & 137.4 & 159.9 \\
\hline \multicolumn{9}{|l|}{$\mathrm{T} 4$} \\
\hline $\mathrm{T} 4$ & 160.3 & 174.2 & 179.9 & 166.5 & 151.6 & 149.4 & 138.6 & 178.2 \\
\hline T4/0.5\% НAp & 161.6 & 176.7 & 182.1 & 165.5 & 152.1 & 149.6 & 140.3 & 173.7 \\
\hline T4/1.0\% НAp & 159.6 & 174.9 & 179.7 & 167.2 & 151.7 & 149.5 & 139.5 & 178.6 \\
\hline $\mathrm{T} 4 / 2.5 \%$ HAp & 162.2 & 175.9 & 180.7 & 144.2 & 152.3 & 149.8 & 140.4 & 158.4 \\
\hline $\mathrm{T} 4 / 5.0 \%$ HAp & 167.0 & 174.6 & 179.4 & 153.0 & 151.6 & 149.6 & 138.7 & 173.9 \\
\hline T4/10.0\% HAp & 157.6 & 176.2 & 180.7 & 124.2 & 152.7 & 151.8 & 147.3 & 165.4 \\
\hline
\end{tabular}

Table 5 some differences in areas of peaks for total, reversing and non-reversing heat flow were observed. For the first heating run area of all peaks are larger for POM/HAp nanocomposites than for pure POM. Similar trends was found for the crystallization process. Moreover, it was observed that the area of peaks increases with a decrease of POM molecular weight. For the second heating run in total and non-reversing heat flow curves, peaks area increases with a decrease of POM copolymer molecular weight, while for reversing heat flow the peaks area is almost constant. These results show that in T4 polyoxymethylene copolymer there is the highest amount of more perfect crystals, while the largest amount of less-perfect crystals is in the T2 copolymer. This effect can be attributed to an increase of degree of crystallinity for POM copolymers with decreasing of average molecular weight which was observed in conventional DSC measurements. The contribution to the apparent reversing heat capacity from melting and crystallization is dependent on the degree of perfection of the crystals. The poorer melt-quenched crystals have a higher reversing 'melting peak' which can thus be used to characterize the crystal perfection of a polymeric material. Poorer crystallized molecules have higher reversing melting contributions and perfect crystals show none. The origin of this reversing melting was linked to a small amount of melted polymer that could not be extracted with solvents [21].

POM has a hexagonal unit cell with unit cell dimensions of $\mathrm{a}=\mathrm{b}=4.45 \AA$ and $\mathrm{c}=17.3 \AA$ [22]. The molecular chains are arranged in a 9/5 helix where $a$ and $b$ axes are on the same plane and the chains are aligned parallel to the $\mathrm{c}$ axis of the crystal [23]. For POM, the calculated positions of the peaks in the $2 \theta$ scan are $22.9^{\circ}, 34.6^{\circ}, 48.4^{\circ}$ and $54.1^{\circ}$ for diffraction planes having Miller indices (100), (105), (115) and (205), respectively [14]. The X-ray diffraction patterns for POM and POM/HAp nanocomposites are shown in Fig. 8.

No shift in $2 \theta$ for pure POM copolymers and all POM/hydroxyapatite nanocomposites was observed, indicating that the addition of HAp does not change the hexagonal system of POM [24]. Figure 7 also shows the $2 \Theta$ vs scattering intensity plots from the (100) plane for POM and POM/HAp nanocomposites after injection moulding. The intensity of the reflections from the (100) plane changes with the HAp content in samples because of the change in the degree of crystallinity [25-27]. For T2 copolymer the highest intensity was observed for pure POM and it decreases with an increase of HAp content. For T3 copolymer similar 
Fig. 6 DSC profiles of POM/

HAp nanocomposites
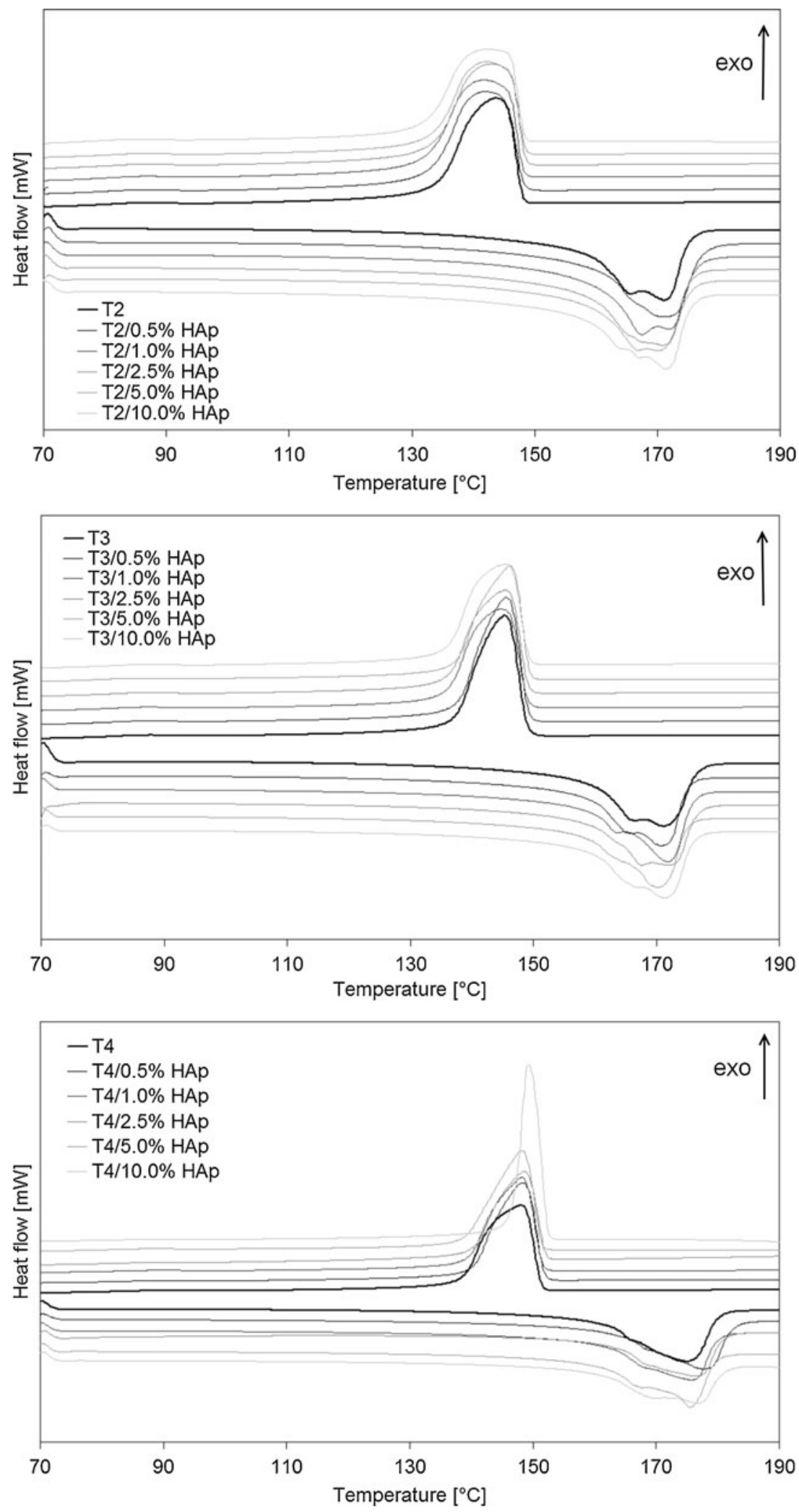

intensities (the highest intensity for T3/0.5\% HAp) were observed for all samples, both pure POM and POM/ HAp nanocomposites. Similar effect as for T3 copolymer was found for T4 copolymer but the highest intensity was observed in T4/1.0\% HAp sample. Some differences between degree of crystallinity calculated form conventional DSC measurements and intensity of reflections from the (100) plane can be attributed to the 
Table 4 Heat of melting and degree of crystallinity of pristine $\mathrm{POM}$ and POM in POM/HAp nanocomposites

\begin{tabular}{|c|c|c|c|c|}
\hline Sample & $\begin{array}{l}\text { POM heat of } \\
\text { melting }[\mathrm{J} / \mathrm{g}] \\
1^{\text {st }} \text { heating run }\end{array}$ & $\begin{array}{l}\text { Degree of } \\
\text { crystallinity [\%] }\end{array}$ & $\begin{array}{l}\text { POM heat of } \\
\text { melting }[\mathrm{J} / \mathrm{g}] \\
2^{\text {nd }} \text { heating run }\end{array}$ & $\begin{array}{l}\text { Degree of } \\
\text { crystallinity }[\%]\end{array}$ \\
\hline \multicolumn{5}{|l|}{$\mathrm{T} 2$} \\
\hline $\mathrm{T} 2$ & 144.7 & 44.3 & 160.75 & 49.26 \\
\hline T2/0.5\% HAp & 149.2 & 45.7 & 164.96 & 50.56 \\
\hline $\mathrm{T} 2 / 1.0 \%$ HAp & 151.2 & 46.3 & 168.53 & 51.65 \\
\hline $\mathrm{T} 2 / 2.5 \%$ HAp & 156.3 & 47.9 & 171.65 & 52.61 \\
\hline Т2/5.0\% НАp & 155.3 & 47.6 & 172.74 & 52.94 \\
\hline $\mathrm{T} 2 / 10.0 \%$ HAp & 162.7 & 49.9 & 191.96 & 58.83 \\
\hline \multicolumn{5}{|l|}{$\mathrm{T} 3$} \\
\hline $\mathrm{T} 3$ & 157.0 & 48.1 & 174.20 & 53.39 \\
\hline Т3/0.5\% НАр & 155.7 & 47.7 & 175.01 & 53.63 \\
\hline T3/1.0\% НAp & 160.2 & 49.1 & 175.59 & 53.81 \\
\hline T3/2.5\% НAp & 160.9 & 49.3 & 178.08 & 54.58 \\
\hline T3/5.0\% НAp & 162.1 & 49.7 & 181.67 & 55.68 \\
\hline T3/10.0\% HAp & 163.0 & 50.0 & 191.00 & 58.54 \\
\hline \multicolumn{5}{|l|}{$\mathrm{T} 4$} \\
\hline $\mathrm{T} 4$ & 166.5 & 51.0 & 186.42 & 57.13 \\
\hline T4/0.5\% НAp & 166.3 & 51.0 & 182.28 & 55.86 \\
\hline T4/1.0\% НAp & 168.9 & 51.8 & 189.24 & 58.00 \\
\hline T4/2.5\% HAp & 147.9 & 45.3 & 185.37 & 56.81 \\
\hline T4/5.0\% НАр & 161.0 & 49.3 & 193.83 & 59.40 \\
\hline T4/10.0\% HAp & 138.0 & 42.3 & 177.40 & 54.37 \\
\hline
\end{tabular}

presence of larger amounts of less perfect crystals as it was observed in TMDSC analysis (Table 5).

POM and its nanocomposites have a very complex morphology consisting of extended chain crystal (ECC) and folded chain crystal (FCC) structures. There are several possible models of stacked lamellar structures of POM: (i) two-phase lamellar stacking model, (ii) coexistence of the main lamellar stacking structure and the stacked lamellae of linear low-molecular weight compound, (iii) insertion model of new lamellae in between the already existing lamellar stacking structure, and (iv) coexistence of the main lamellar stacking structure and the stacked lamellae of macrocyclic compounds [28]. In the cooling process from the melt the infrared bands characteristic of POM folded chain crystal morphology appeared around $156^{\circ} \mathrm{C}$, followed by a gradual increase of infrared bands of extended chain crystals around $140^{\circ} \mathrm{C}$ [29]. POM samples prepared by cooling from the melt exhibits the ECC bands more clearly, allowing to speculate that the POM sample crystallized from the melt is a mixture of ECC and FCC in a complicated manner. It was assumed that lamellar stacking structure formed in the temperature region I (primary crystallization) becomes tighter in the temperature region II (secondary crystallization) by a generation of second lamellae in between the original lamellae [30, 31].
The infrared spectra of POM are known to be highly sensitive to the morphology of the crystallites, and for example, Shimomura and Iguchi [32-35] discovered a remarkable difference in the infrared spectra between ECC and FCC. Moreover, they found that the lamellar stacking structure formed during primary crystallization becomes tighter during secondary crystallization by a generation of second lamellae in between the original lamellae - the lamellar insertion model was adopted here as the most possible structure model of POM sample crystallized from the melt. Moreover, the fully extended chains may be produced by applying tensile or shear stress along the chain axis during the crystallization process [30].

The infrared spectra taken for the POM and POM/HAp nanocomposites are shown in Fig. 9.

Characteristic bands both for ECC and FCC were observed in spectral profiles of POM and POM/HAp nanocomposites, but there were no significant differences in shape of spectral profiles between pure POM and POM/ HAp nanocomposites - it means that in nanocomposite samples POM also crystallize as FCC and ECC.

Due to their microstructural properties, semicrystalline polymers generally present the ability to undergo large plastic strains. Typical stress-strain curves and mechanical parameters of POM and POM/HAp 

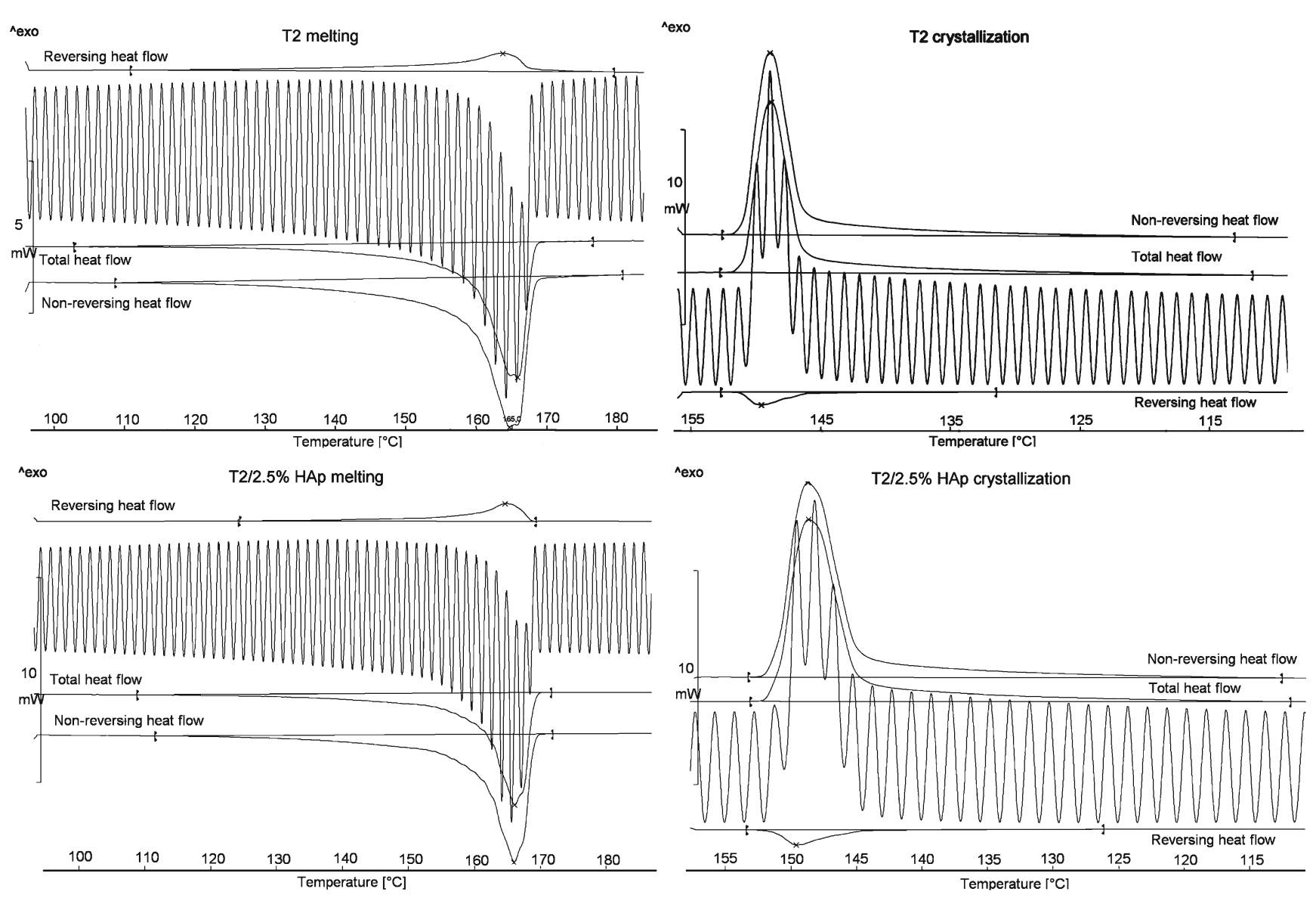

Fig. 7 TMDSC curves of $\mathrm{T} 2$ and $\mathrm{T} 2 / 2.5 \%$ HAp nanocomposites

nanocomposites vs hydroxyapatite concentration are shown in Fig. 10 and Table 6.

The main hypothesis considers the global evolution of stresses and strains as a result of mechanical interactions between the solid, crystalline and tied amorphous phase of the semi-crystalline polymer, and the soft fluid-like part of the amorphous polymer. The second assumption postulates the existence of viscous and plastic microscopic phenomena acting on the solid phase [13]. The tensile strength observed for many semi-crystalline polymers is an intermediate peak on the stress-strain profiles. This corresponds to the point where uniform deformation of the specimen changes to non-uniform deformation, resulting in yielding (necking) at a critical elongation [36]. The initial response of a polymeric crystal when a tensile force is applied is to deform elastically. As in the amorphous polymer, the folded chains of crystal can elongate their atomic bonds to produce a reversible

Table 5 Results of the TMDSC measurements for melting and crystallization processes of POM and POM/2.5\% HAp nanocomposites

Sample Total heat Non-revers. Revers. heat Total heat Non-revers. Revers. heat Total heat Non-revers. Revers. heat flow $[\mathrm{J} / \mathrm{g}]$ heat flow $[\mathrm{J} / \mathrm{g}]$ flow $[\mathrm{J} / \mathrm{g}]$ flow $[\mathrm{J} / \mathrm{g}]$ heat flow $[\mathrm{J} / \mathrm{g}]$ flow $[\mathrm{J} / \mathrm{g}]$ flow $[\mathrm{J} / \mathrm{g}]$ heat flow $[\mathrm{J} / \mathrm{g}]$ flow $[\mathrm{J} / \mathrm{g}]$ Melting $1^{\text {st }}$ run Crystallization Melting 2nd run

\begin{tabular}{llllllllll}
\hline T2 & 145.8 & 177.8 & 33.2 & 145.8 & 156.0 & 10.7 & 156.1 & 188.5 & 29.2 \\
T2/2.5\% HAp & 149.9 & 187.2 & 38.5 & 148.6 & 157.6 & 9.8 & 162.2 & 192.1 & 31.6 \\
T3 & 152.8 & 194.2 & 42.1 & 151.9 & 162.9 & 10.5 & 165.1 & 194.1 & 28.5 \\
T3/2.5\% HAp & 155.7 & 193.5 & 39.1 & 156.7 & 166.9 & 10.5 & 170.5 & 198.9 & 27.8 \\
T4 & 156.3 & 196.2 & 39.4 & 165.6 & 175.1 & 10.8 & 173.5 & 202.6 & 29.5 \\
T4/2.5\% HAp & 161.0 & 208.8 & 47.7 & 164.3 & 176.1 & 11.8 & 180.4 & 206.7 \\
\hline
\end{tabular}



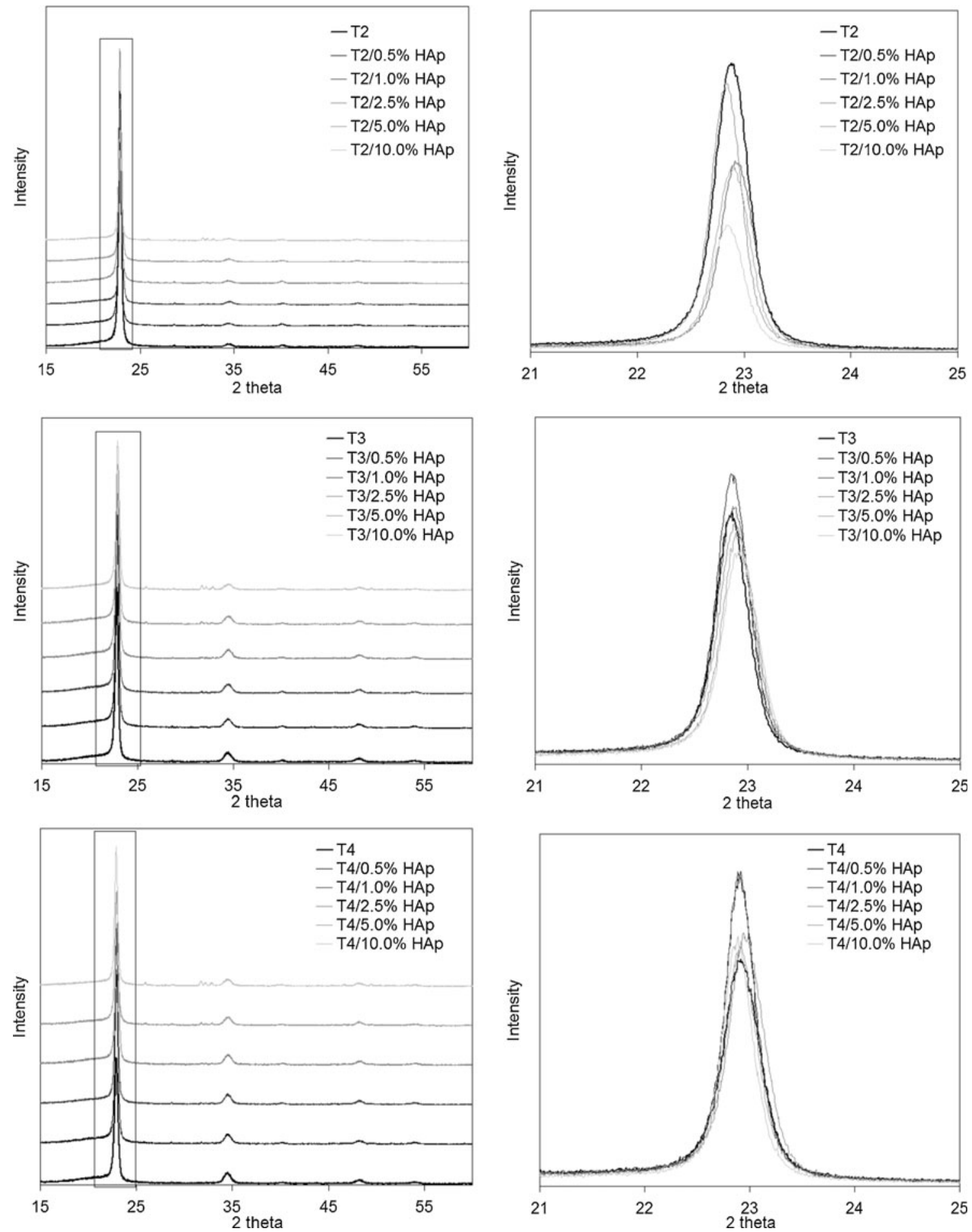

Fig. 8 WAXD diffraction patterns of POM and POM/HAp nanocomposites

deformation. Spherulites changes uniformly from a sphere to an ellipse with the relative spatial relationships of all lamellae and fibrils maintained. Plastic deformation within a crystal is begun when the lamellae move relative to one other-they orient its straight chains in same directions as the applied force. Once the lamellae have begun to slip relative to one another, they then will tilt so as to further align themselves in direction of the applied force. It causes a great strain on the tie molecules and finally, the tie molecules become almost fully extended and the slip process nears completion-polymer reaches yield point [37]. 

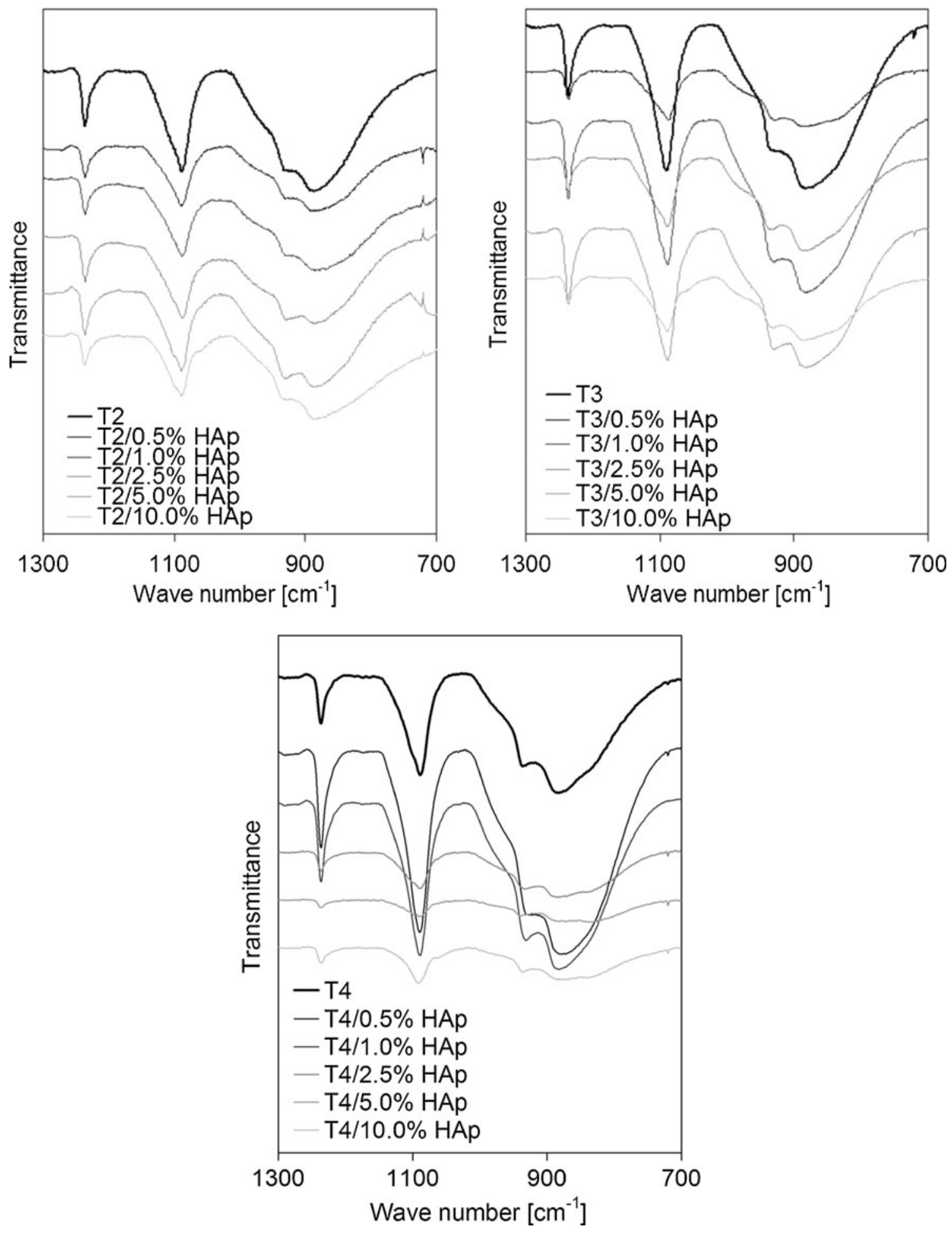

Fig. 9 FTIR-ATR spectra of POM and POM/HAp nanocomposites

Generally, it can be seen that Young's modulus increases with increasing hydroxyapatite concentration, elongation at break decreases with increasing HAp concentration and tensile strength decreases slightly with HAp concentration for all POM copolymers. The change in mechanical properties is the result of the changes in crystal size owing to the existence of the nucleating agent HAp and changes in samples morphology. Samples with highest degree of crystallinity (i.e. with lowest average molecular weight) have lower Young's modulus 
Fig. 10 Strain-stress curves for $\mathrm{POM}$ and POM/HAp

nanocomposites
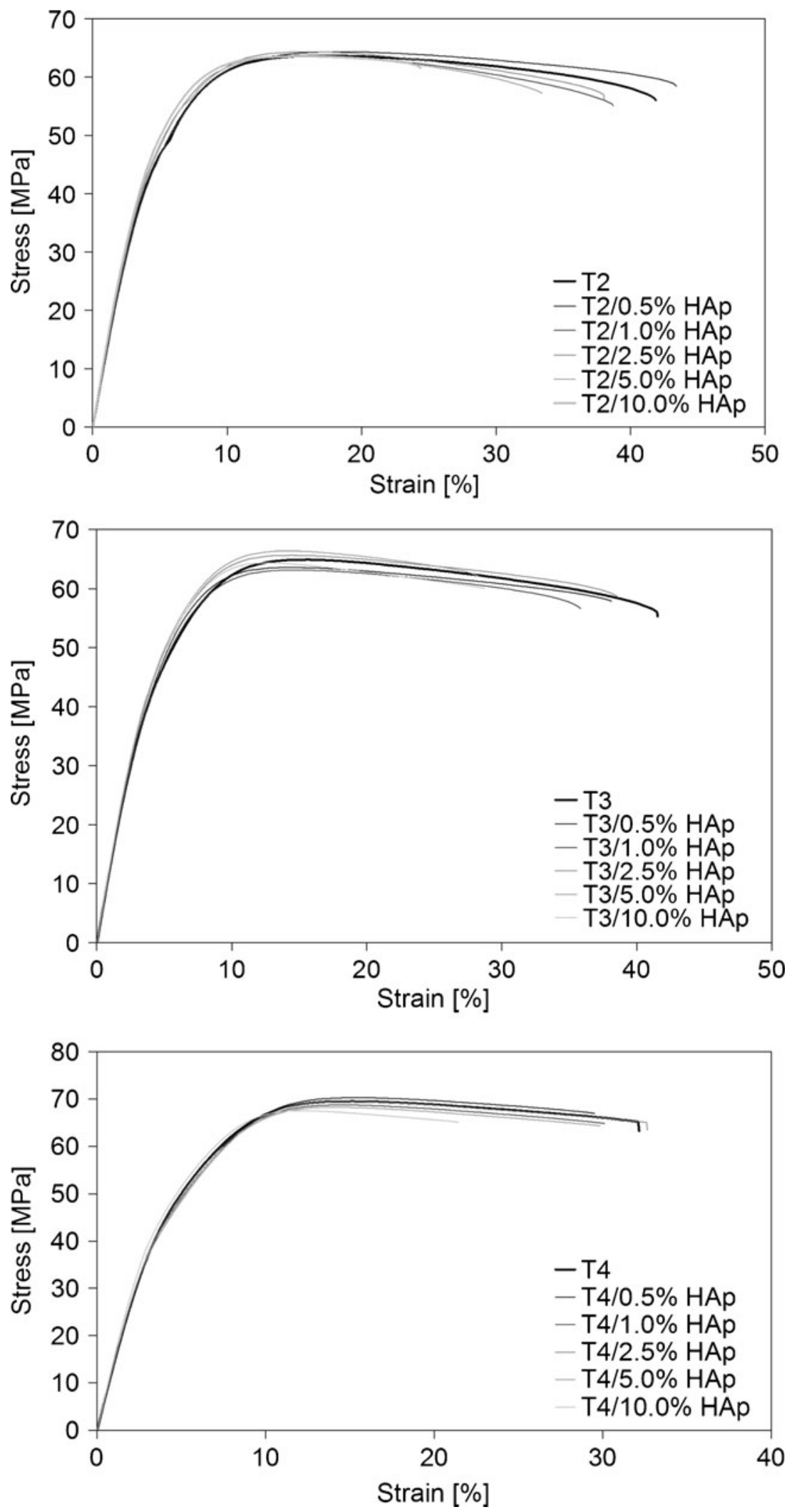

and higher elongation at break. Moreover, during tensile tests whitening and some elongations at break with small necking was observed mainly for $\mathrm{T} 2$ and $\mathrm{T} 3$ copolymer and their nanocomposites, but with increasing HAp concentration smaller necking effect was observed. For T4 copolymer and its nanocomposites more brittle breaking 
Table 6 Tensile properties of POM and POM/HAp nanocomposites

\begin{tabular}{|c|c|c|c|c|c|c|}
\hline Sample & $\mathrm{Rm}[\mathrm{MPa}]$ & Standard deviation & e Fmax [\%] & Standard deviation & $\mathrm{E}[\mathrm{MPa}]$ & Standard deviation \\
\hline \multicolumn{7}{|l|}{$\mathrm{T} 2$} \\
\hline $\mathrm{T} 2$ & 63.53 & 1.17 & 17.69 & 0.93 & 1121.93 & 59.52 \\
\hline T2/0.5\% НAp & 65.60 & 1.84 & 17.81 & 0.55 & 1159.36 & 22.79 \\
\hline T2/1.0\% HAp & 64.39 & 0.74 & 16.42 & 0.84 & 1147.11 & 21.51 \\
\hline T2/2.5\% HAp & 64.36 & 1.17 & 16.91 & 1.09 & 1171.99 & 27.51 \\
\hline T2/5.0\% HAp & 64.03 & 0.85 & 16.42 & 0.80 & 1172.02 & 34.81 \\
\hline T2/10.0\% HAp & 64.75 & 0.71 & 15.72 & 0.83 & 1238.30 & 18.10 \\
\hline \multicolumn{7}{|l|}{$\mathrm{T} 3$} \\
\hline $\mathrm{T} 3$ & 66.03 & 1.72 & 15.62 & 0.06 & 1190.49 & 37.09 \\
\hline T3/0.5\% HAp & 64.11 & 0.28 & 14.74 & 0.40 & 1180.07 & 8.90 \\
\hline T3/1.0\% HAp & 64.56 & 0.76 & 15.20 & 0.44 & 1181.24 & 15.96 \\
\hline $\mathrm{T} 3 / 2.5 \%$ HAp & 66.75 & 0.65 & 14.76 & 0.79 & 1208.70 & 14.12 \\
\hline T3/5.0\% HAp & 65.84 & 0.94 & 14.63 & 0.55 & 1178.92 & 63.10 \\
\hline T3/10.0\% HAp & 65.53 & 0.57 & 12.90 & 0.19 & 1263.46 & 2.40 \\
\hline \multicolumn{7}{|l|}{$\mathrm{T} 4$} \\
\hline $\mathrm{T} 4$ & 70.10 & 1.42 & 15.32 & 0.28 & 1283.07 & 6.89 \\
\hline T4/0.5\% HAp & 70.23 & 0.77 & 15.13 & 0.11 & 1294.86 & 22.72 \\
\hline T4/1.0\% HAp & 68.86 & 0.70 & 15.11 & 0.26 & 1291.37 & 19.40 \\
\hline T4/2.5\% HAp & 69.98 & 0.29 & 14.66 & 0.54 & 1303.92 & 15.37 \\
\hline T4/5.0\% HAp & 67.62 & 1.17 & 14.47 & 0.44 & 1287.53 & 33.83 \\
\hline T4/10.0\% HAp & 67.13 & 0.87 & 12.51 & 0.33 & 1365.53 & 57.76 \\
\hline
\end{tabular}

was observed due to the highest degree of crystallinity for these samples.

\section{Conclusions}

POM/HAp nanocomposites for bone long-term implants have been obtained by melt processing. TEM observations proves good HAp dispersion in polymer matrix. The highest melting temperature and degree of crystallinity were found for T4 copolymer and its nanocomposites due to the lowest molecular weight. On the other hand, TMDSC measurements show the largest amount of reversible melting for T4 copolymer. This effect can be attributed to the largest concentration of end groups and, in consequence, to formation of less perfect crystal structures, as well as the highest mobility of shorter polymer chains. Moreover, for all investigated samples, no shift in $2 \theta$ for pure POM and POM with hydroxyapatite was observed, indicating that the addition of HAp does not change the hexagonal system of POM. Young's modulus was found to increase with molecular weight of POM copolymer and with HAp concentration, whereby elongation at break and tensile strength decrease with an increase of POM molecular weight and with an increase of HAp content.
Acknowledgments The autor is grateful to the Polish Ministry of Science and Higher Education for financial support under the grant No. PBZ/MEiN/01/2006/15.

Open Access This article is distributed under the terms of the Creative Commons Attribution Noncommercial License which permits any noncommercial use, distribution, and reproduction in any medium, provided the original author(s) and source are credited.

\section{References}

1. Barker SJ, Price MB (1970) Polyacetals. Plastics Institute, London

2. Zhang Q, Chen Y (2011) J Polym Res 18:293-303

3. Wu S (1970) Polym Prepr 11:1291

4. Uthaman RN, Pandurangan A, Majeed SSMA (2007) J Polym Res 14:441-447

5. He J, Zhang L, Li Ch (2010) Polym Eng Sci 50:2153

6. Kawaguchi K, Masuda E, Tajima Y (2008) J Appl Polym Sci 107:667

7. Thompson MS, Northmore-Ball MD, Tanner KE (2001) J Mater Sci Mater Med 12:883

8. Thompson MS (2001) The design of a novel hip resurfacing prosthesis. $\mathrm{PhD}$ thesis, London

9. Dumbleton JH (1981) POM/Metal joint prostheses. In: Dumbleton JH (ed) Tribology of natural and artificial joints. Elsevier, Amsterdam

10. Bouyer E, Gitzhofer F, Boulos MI (2000) J Mater Sci Mater Med 11:523

11. Lee HJ, Kim SE, Choi HW et al (2007) Eur Polym J 43:1602

12. Pielichowska K, Błażewicz S (2010) Adv Polym Sci 32:97-210 
13. Lazzeri A, Marchetti A, Levita G (1997) Fatig Fract Eng Mater Struct 20:1207-1216

14. Bershtein VA, Egorova LM, Egorov VM, Peschanskaya NN, Yakushev PN, Keating MY, Flexman EA, Kassal RJ, Schodt KP (2002) Thermochim Acta 391:227

15. Jaffe M, Wunderlich B (1967) Kolloid ZZ Polym 216-217:203

16. http://athas.prz.rzeszow.pl/

17. Wunderlich B (1980) Macromolecular physics, 3. Academic, New York

18. Reading M (1993) Trends Polym Sci 1:248

19. Sauer BB, Kampert WG, Blanchard N, Threefoot SA, Hsiao BS (2000) Polymer 41:1099

20. Okazaki I, Wunderlich B (1997) Macromol Rapid Commun 18:313

21. Okazaki I, Wunderlich B (1997) Macromolecules 30:1758

22. Carazzolo GA (1963) J Polym Sci Part A General Papers 1:1573

23. Tadokoro H, Yasumoto T, Murashashi S, Nitta J (1960) J Polym Sci 44:266
24. Xu WB, He PS (2001) Polym Eng Sci 41:1903

25. Maeda Y, Nakayama K, Kanetsuna H (1982) Polym J 14:649

26. Taraiya K, Unwin AP, Ward IM (1988) J Polym Sci Part B Polym Phys 26:817

27. Mohanraj J, Bonner MJ, Barton DC, Ward IM (2006) Polymer 47:5897

28. Hama H, Tashiro K (2003) Polymer 44:6973

29. Hama H, Tashiro K (2003) Polymer 44:3107

30. Hama H, Tashiro K (2003) Polymer 44:2159

31. Chang FC, Yang MY (1990) Polym Eng Sci 30:543

32. Iguchi M, Murase I (1975) J Polym Sci Polym Phys 13:1461

33. Shimomura M, Iguchi M (1982) Polymer 23:509

34. Shimomura M, Iguchi M, Kobayashi M (1988) Polymer 29:351

35. Brusselle-Dupend N, Cangémi L (2008) Mech Mater 40:743

36. Robeson M (2007) Polymer blends: A comprehensive review. Carl Hansen Verlag, Munich

37. Daniels CA (1989) Polymers: structure and properties. Technomic Publishing Company, Lancaster 